\title{
REFLEXÕES SOBRE A EDUCAÇÃO E EMANCIPAÇÃO NOS ESPAÇOS FORMATIVOS À LUZ DOS FUNDAMENTOS DA TEORIA CRÍTICA
}

Profa. Dra. Marta Regina Furlan de Oliveira - UEL

\section{RESUMO}

Este estudo objetiva refletir sobre o processo de educação e emancipação nos espaços educacionais, tendo como embasamento teórico os fundamentos da Teoria Crítica, principalmente, com as discussões em Adorno e Horkheimer. O estudo é fruto das reflexões relacionadas ao Projeto de Pesquisa - "Indústria Cultural, Educação e Trabalho Docente na Primeira Infância: da semiformação à emancipação humana" da Universidade Estadual de Londrina na qualidade de coordenadora. Nessa discussão, percebe-se que os equívocos decorrentes das teorias modernas da pedagogia e da educação tem influenciado as práticas educativas escolares, contribuindo efetivamente para o aprisionamento intelectual e pedagógico tanto dos profissionais quanto dos alunos envolvidos. Destes equívocos, pode-se verificar a fragilidade do conceito de educação e emancipação em que são destinados os trabalhos pedagógicos e escolares; ainda, a crise da autoridade pedagógica elucidada por Hannah Arendt em sua obra "Entre o passado e o futuro". Acredita-se, deste modo, que as inquietações apresentadas neste texto suscitam-nos a repensar a escola e os conceitos de educação e emancipação tão fragilmente utilizados nos discursos pedagógicos e, ainda, direcionar nossas reflexões para novos horizontes formativos voltados para a auto crítica e auto reflexão, tendo como propósito maior, o processo de emancipação humana.

Palavras-Chave: Educação. Emancipação. Teoria Crítica.

\section{INTRODUÇÃO}

O texto tem o propósito de refletir acerca do processo de educação e emancipação nos espaços formativos, tendo como fundamento a Teoria Crítica em Adorno e Horkheimer em diálogo as contribuições de Hannah Arendt com sua obra "Entre o passado e o futuro". O estudo é fruto das reflexões relacionadas ao Projeto de Pesquisa - "Indústria Cultural, Educação e Trabalho Docente na Primeira Infância: da semiformação à emancipação humana" da Universidade Estadual de Londrina na qualidade de coordenadora.

Ao refletir acerca dos espaços formativos contemporâneos voltados ao trabalho educativo escolar, tem-se a preocupação acerca de como vem sendo constituído os conceitos de educação, emancipação e autoridade pedagógica. No que se refere aos conceitos de educação e emancipação, é notório pensar que esses conceitos são frutos de um processo semiformativo, em que a educação é reduzida ao pensamento sem reflexão crítica e que se adapta aos moldes da Indústria Cultural. Esse modelo social e educativo leva o indivíduo a abdicar, pelo processo de adaptação e aceitação humana, às possibilidades de uma formação emancipatória, a auto determinação e auto crítica; conformando-se aos padrões sociais e econômicos da sociedade vigente. 


\section{SEMINÁRIO DE PESQUISA EM CIÊNCIAS HUMANAS - SEPECH \\ Humanidades, Estado e desafios didático-científicos \\ Londrina, 27 a 29 de julho de 2016}

No que se refere ao conceito de autoridade pedagógica, as contribuições de Hannah Arendt (2003) são atuais e urgentes, uma vez que nos leva a pensar nos equívocos de compreensão do próprio conceito, principalmente nos espaços formativos. Esses equívocos são decorrentes da própria teoria moderna da pedagogia e educação que influenciam significativamente as práticas educativas escolares, em que a crise da autoridade pedagógica fragiliza a formação humana e o próprio processo de aprendizagem e conhecimento na vida de crianças e adolescentes.

O conceito de autoridade pedagógica, segundo a autora, ora é traduzido pelo autoritarismo pedagógico ou superioridade do adulto ${ }^{l}$ com práticas educativas cerceadoras do conhecimento; ora está voltado ao processo de neutralização $e$ silenciamento formativo da razão, com ações sem intencionalidade e distantes do que deveria ser o propósito educacional com vistas a emancipação. Diante disso, o indivíduo fica sujeitado à dominação, com a incapacidade de conquistar a autonomia intelectual ou a emancipação. $\mathrm{O}$ conhecimento, aliado à posse de modernos aparatos tecnológicos, torna-se um dos propagadores da crise da autoridade quando, ao invés de libertar o homem dos processos semiformativos, ao contrário, contribui para a transformação do homem em objeto da dominação, fazendo-o refém da indústria cultural ${ }^{2}$ e dos processos semiformativos.

Neste contexto, assistimos ao declínio da razão e da autoridade pedagógica face ao mundo cada vez mais avançado tecnologicamente. Pode-se ousar afirmar que a autoridade foi recusada pelos adultos, sendo que estes, se recusam a assumir a responsabilidade pelo mundo ao qual trouxeram as crianças. A própria autoridade estabelecida no mundo moderno, sejam elas a autoridade paterna e pedagógica estão sendo sucumbindo aos ditames semiformativos à luz da Indústria Cultural e da neutralização da razão. $\mathrm{O}$ que seria de responsabilidade para o homem moderno sobre a vida da criança, se perdeu, quando este se infantilizou frente à adaptação e ao conformismo humano. O homem moderno, seduzido pelos fetiches da técnica e da mercadoria, está cada vez mais se eximindo de tal empreitada de autoridade.

Diante disso, a empreitada filosófica no campo educativo está em renovar olhares, perspectivas e compreensões que venham oferecer novos direcionamentos pedagógicos voltados para uma formação humana mais digna e autônoma.

\section{OS ESPAÇOS FORMATIVOS E A CRISE DA AUTORIDADE PEDAGÓGICA}

Hannah Arendt (2013), no texto Que é Autoridade? aponta para a crise da autoridade como movimento típico do mundo moderno, relacionado historicamente à perda da tradição, ou seja, à crise nos conceitos universais: autoridade e liberdade, que para o mundo grego, eram sinônimos de responsabilidade e cuidado para com os valores históricos e humanos. Seus estudos trazem implicações significativas no campo da

\footnotetext{
${ }^{1}$ Esse termo é utilizado por Hannah Arendt no ensaio A Crise na Educação publicado em versão alemã em $1957 \mathrm{em}$ Fragwürdige Traditionsbestände im Politischen Denken der Gegenwart, Frankfurt.

${ }^{2}$ Esse termo foi utilizado pela primeira vez, por Horkheimer e Adorno, no ensaio, Indústria Cultural: iluminismo como sedução das massas, publicado em 1947, cuja expressão é apontada por Adorno (1977) como uma cultura que serve aos interesses do capitalismo, que a partir da revolução tecnológica redefine as condições de produção e reprodução da cultura.
} 


\section{SEMINÁRIO DE PESQUISA EM CIÊNCIAS HUMANAS - SEPECH \\ Humanidades, Estado e desafios didático-científicos \\ Londrina, 27 a 29 de julho de 2016}

educação, dando uma atenção especial ao ensino e ao papel da autoridade pedagógica no trabalho educativo.

Arendt chama a atenção para a crise das autoridades tradicionais, concordando que a crise constante da autoridade acompanha o desenvolvimento do mundo moderno em nosso século, afetando as relações entre a autoridade familiar e a pedagógica ${ }^{3}$. A autora afirma que o fim da tradição que aconteceu com o advento da modernidade não é especulação nem é um juízo de valor, mas um fato politicamente palpável. Com isso, ela quer dizer que, com a modernidade, as comunidades políticas deixaram de ser sustentadas pelos valores e costumes tradicionais ${ }^{4}$. A tradição perdeu o poder de organizar e dar um sentido para a vida política e comunitária. Os valores tradicionais, que antes reuniam os valores máximos da humanidade, perderam a validade objetiva e foram desmascarados como parciais e ideológicos. Afirma, ainda, que o sintoma mais significativo da crise, "pela sua profundeza e seriedade" é ter se espalhado no campo familiar, com a educação dos filhos, e na educação, com os espaços formativos (ARENDT, 2013 p.128).

A razão, na medida em que se tornou critério para o exercício do poder, perdeu a sua dimensão contemplativa, e a sua autonomia, relacionada ao conhecimento e à compreensão do real, transformou-se em instrumento, em meio para submetê-lo e controlá-lo. Com a perda da tradição não se perde o passado, mas se perde "o fio que nos guiou com segurança pelos vastos domínios do passado" (ARENDT, 2013 p.130). A tradição, a despeito da errônea identificação com a religião não é o passado, mas a memória, que resguarda a profundidade da existência humana. Sem memória, sem experiência, não há consistência no desenvolvimento dos processos educacionais. Somos ameaçados pelo esquecimento e, mergulhados no calor irracional e acrítico da multidão (ARENDT, 2013). Reina a ilusão mediada por mecanismos sedutores da indústria cultural, conduzindo, nos sujeitos o desenvolvimento da personalidade voltada a extraordinária superficialidade do pensamento e sua incapacidade de desenvolver experiência do pensar. Essa afirmativa de Arendt me faz pensar sobre o conceito de "insossa sabedoria" utilizado por Adorno e Horkheimer em Dialética do Esclarecimento (1985) ao se referir ao processo semiformativo e ou superficialidade do pensar.

A insossa sabedoria para a qual não há nada de novo sob o sol, porque todas as cartas do jogo sem-sentido já teriam sido jogadas, porque todos grandes pensamentos já teriam sido pensados, porque as descobertas possíveis poderiam ser projetadas de antemão, e os homens estariam forçados a assegurar a autoconservação pela adaptação.

Assim, a autora afirma que a autoridade desapareceu do mundo moderno em função de uma crise constante. Entretanto, a autora formula uma definição do conceito de autoridade que pode ser compreendido "a-historicamente", ou seja, apesar de tal conceito ter sido pensado sobre uma base de experiências históricas determinadas, ele possui um conteúdo, uma natureza e uma função definidos, passíveis de serem

\footnotetext{
${ }^{3}$ Neste caso deter-nos-emos ao conceito de autoridade nos espaços educativos escolares.

4 O fim da tradição com o surgimento da modernidade é um tema recorrente em Arendt. Está em seu livro Entre o passado e o futuro, principalmente no prefácio intitulado "A quebra entre o passado e o futuro" e no capitulo "A tradição e a época moderna" (ARENDT, 2013).
} 


\section{SEMINÁRIO DE PESQUISA EM CIÊNCIAS HUMANAS - SEPECH \\ Humanidades, Estado e desafios didático-científicos \\ Londrina, 27 a 29 de julho de 2016}

compreendidos na atualidade, mesmo apesar do suposto fenômeno de desaparecimento da autoridade do mundo moderno (ARENDT, 2013).

Em suas reflexões, esclarece que nem autoridade é compatível com tirania, nem tradição é exatamente o mesmo que passado. Nesse sentido, a crise da autoridade foi originariamente política, com os movimentos políticos e as formas de governo totalitárias surgidas durante a primeira metade do século XX. Entretanto, essa crise se espalha também em áreas pré-políticas, tais como a criação dos filhos e a educação "onde a autoridade no sentido mais lato sempre fora aceita como uma necessidade natural" (ARENDT, 2013, p.128). A ruína "mais ou menos geral e mais ou menos dramática de todas as autoridades tradicionais" foi o grande substrato possibilitador da ocorrência generalizada de governos totalitários a partir do início deste século.

Além de dedicar-se à reflexão sobre a crise da autoridade, Arendt procura compreender como se estabelece uma autoridade legítima, e se essa legitimidade não reside na violência e/ou na força, ela também não reside na persuasão, pois persuadir implica que a relação se estabeleça numa esfera de igualdade, haja vista que a eficiência da ordem se dá pelo melhor argumento. Arendt acredita, desse modo, que uma relação mediada pela violência angaria obediência, mas uma obediência por medo e não por respeito não pode ser considerada como um projeto de autoridade e de educação. Sobre esse ponto, podemos afirmar que, muitas vezes, cria-se uma cultura escolar do medo e da punição, inibindo em crianças e alunos em geral a verdadeira consciência do que seja autoridade.

Nesse sentido, Arendt procura esclarecer o conceito de autoridade diferenciando-o de outras relações entre os indivíduos que implica obediência, como a força e a violência. De fato, busca as origens do conceito e sua utilização com as contribuições dos romanos, na tarefa de desvendar os equívocos de compreensão desse conceito. Afirma a autora, que se a autoridade exigir obediência, então ela perdeu seu sentido de autoridade. "Contudo a autoridade exclui a utilização de meios externos de coerção; onde a força é usada, a autoridade em si fracassou" (ARENDT, 2013 p.129).

Aponta a crise da autoridade como pano de fundo para a transformação dos movimentos políticos totalitários do século XX. Neste contexto, a experiência totalitária produziu uma situação absolutamente nova, sem condições de inteligibilidade a partir dos padrões tradicionais de compreensão. A ideia de governo total era inerente à eliminação da política e o terror, o medo, o silêncio e a solidão eram os sustentáculos dessa tentativa de governo (ARENDT, 2013).

É necessário que nossos horizontes pedagógicos sejam ampliados, no intuito de refletir a atual crise como um fenômeno social e político e, não restritamente local, fragmentado. Os adultos (sejam eles pais ou professores) estão se negando a assumir a responsabilidade de ensinar e orientar as crianças e jovens acerca do mundo e da responsabilidade que as palavras e ações humanas assumem. Diante disso, a função da escola é ensinar às crianças como o mundo é, e não instruí-las na 'arte de viver'. Sua argumentação é a favor da autoridade na sala de aula e sua visão educativa é assumidamente conservadora. Isso não quer dizer que ela defenda um professor autoritário, tampouco é favorável à escola como um agente da manutenção da ordem estabelecida; ao contrário, a autora acreditava que a criança desde seu início deve ser apresentada ao mundo e estimulada a mudá-lo pelo processo de educação e emancipação que Adorno tão claramente defende. 


\section{SEMINÁRIO DE PESQUISA EM CIÊNCIAS HUMANAS - SEPECH \\ Humanidades, Estado e desafios didático-científicos \\ Londrina, 27 a 29 de julho de 2016}

Diante disso, compreender a crise de autoridade elucidada por Hannah Arendt abre novos horizontes pedagógicos em favor de uma educação mais crítica e emancipatória, a fim de encontrarmos fundamentos que possam ajudar a construir conceitos teóricos e pedagógicos com a qual se apontem possibilidades para a liberdade humana e para a experiência crítica do pensar.

Ora, não é de se estranhar que a própria Arendt levante três ideias básicas que poderiam justificar essa "catástrofe" política e educacional que é a crise da autoridade. Segundo a autora, a primeira é que criaram-se uma sociologia de valorização da infância e do ser criança que lhe dá o direito de assumir uma autonomia desde o início, enquanto que, os adultos vão desincumbidos por sua responsabilidade na educação e orientação pedagógica para o exercício do pensar e da consciência. Nesta lógica de pensamento, muitos profissionais envolvidos na educação acreditam que o papel dos adultos deve então consistir em limitar-se a assistir a esse processo, ou seja, é o grupo das crianças ele mesmo que detém a autoridade que vai permitir dizer a cada criança o que ela deve e não deve fazer. Nesse sentido, podemos dizer que o primeiro pressuposto básico leva em conta somente o grupo, e não a criança individual.

O segundo pressuposto básico está relacionado ao ensino, pois este é influenciado pelas contribuições modernas da psicologia e pelas doutrinas pragmáticas que acabaram alterando os conceitos relacionados à pedagogia e à educação. A perspectiva pragmática da educação gera fragilidades no que se refere a autoridade pedagógica e ao ensino crítico, propriamente dito. Há um esvaziamento dos conceitos críticos em detrimento de concepções infundadas de aprendizagem e de conhecimento escolar. Essa realidade afeta os espaços formativos voltados a primeira infância, já que o próprio pragmatismo está novamente na "moda", em que se afirmam e reafirmam à luz de conceitos superficiais das teorias modernas na tentativa de responder questões do ensino e da aprendizagem.

O cenário descrito acima nos leva ao terceiro pressuposto anunciado por Arendt devido ao uso acrítico pela escola da teoria moderna de aprendizagem, em que pelo processo de incorporação dos modismos pedagógicos, os espaços formativos abriram as janelas para as ideologias de ensino e aprendizagem. Respaldados por conceitos arendtianos podemos inferir que nesta perspectiva de aprendizagem "só é possível conhecer e compreender aquilo que nos mesmos fizermos, e sua aplicação à educação é tão primária quanto óbvia", ou seja, apresentamos a nova forma de ensinar e aprender que "consiste em substituir, na medida do possível, o aprendizado pelo fazer" que nada mais é do que a tão anunciada - pedagogia ativa ou pedagogia do fazer.

Essa lógica de aprendizagem é muito usual nos espaços educativos voltados à primeira infância, quando o ativismo supera o conteúdo e a reflexão. Pode-se dizer que há uma busca sem limites por "fazeres", por "saberes" em que, principalmente os professores ficam deslumbrados pelo mundo do receituário educativo. Essa prática é tão naturalizada no campo da educação, que se transformou no grande lema educacional, que se traduz na redução do saber ao fazer. Essa proposta ativista acaba sendo mal conduzida nos espaços formativos, principalmente quando confundida com a manipulação motora dos objetos e materiais ou produção de atividades manuais, por exemplo. Há também a intenção de criar, com as reformas educativas, um novo modelo de escola, agora a escola lúdica, do espetáculo, pelo processo do brincar, da ludicidade em que acaba sendo banalizado o conhecimento como algo que esteja próximo à diversão. 


\section{SEMINÁRIO DE PESQUISA EM CIÊNCIAS HUMANAS - SEPECH \\ Humanidades, Estado e desafios didático-científicos \\ Londrina, 27 a 29 de julho de 2016}

O pensamento, portanto, é convertido em mero conhecimento prático ou ativista. Podemos, assim, dizer que os fatos recentes na educação de crianças traduzem efetivamente o divórcio entre o conhecimento técnico e o conhecimento emancipador. Há nesse processo, um endeusamento pelos modelos, pelas técnicas, pelas atividades em si; sem se prender à busca pelo conhecimento dos conceitos e pela razão crítica.

Sobre esse assunto Horkheimer nos dá a seguinte contribuição:

Tendo cedido em sua autonomia, a razão tornou-se um instrumento. [...] A razão tornou-se algo inteiramente aproveitado no processo social. Seu valor operacional, seu papel no domínio dos homens e da natureza tornou-se o único critério para avalia-la. [...] Os conceitos foram "aerodinamizados", racionalizados, tornaram-se instrumentos de economia de mão-de-obra. É como se o próprio pensamento tivesse se reduzido ao nível do processo industrial, submetido a um programa estrito, em suma, tivesse se tornado uma parte e uma parcela da produção (HORKHEIMER, 2002 p.26).

Ao contrário desta visão educativa, o aluno precisa ser instigado ao conhecimento e à busca crítica do pensar pelo processo do ensino e aprendizagem. Os professores envolvidos devem se assumir na responsabilidade de educar e de instigar o conhecimento emancipado. Arendt aponta que há uma aceitação servil e acrítica nas mais modernas teorias pedagógicas como se fossem capazes de superar as fragilidades do ensino e resolver todos os problemas enfrentados nos espaços formativos. Outro ponto problemático é que na busca pela valorização das diferenças, a escola acaba cometendo um grande equívoco: ao igualar ou apagar tanto quanto possível a diferença entre velhos e novos, entre dotados e não dotados, enfim, entre professores e crianças, o processo de nivelamento educativo articula-se com a perda da autoridade pedagógica.

\section{2. É POSSÍVEL EDUCAÇ̃̃o E EMANCIPAÇ̃̃O?}

Quando nos remetemos aos processos formativos, podemos afirmar que houve avanços filosóficos, políticos e pedagógicos no trabalho pedagógico, entretanto, prevalece a crença de que estas mudanças estejam alicerçadas por aquisições materiais e instrumentais (jogos, ambiente planejado, material apostilado) todavia, enfrentamos os mesmos problemas de sempre: professores fragilizados de conhecimento (semiformação); falta de referência e de autoridade pedagógica em sala de aula (sem preparo didático e afetivo-emocional); declínio da razão objetiva, deixando-se levar por práticas equivocadas no trabalho com os educandos.

Embora haja as formações continuadas voltadas ao trabalho pedagógico docente, muitos profissionais não se assumem enquanto autoridade pedagógica, ou seja, como um profissional responsável pelo conhecimento e pela formação humana; ainda há os que são iludidos pelas ilusões de autoridade que na prática traduzem efetivamente a superioridade do adulto sobre a criança com ações inibidoras, de humilhação e autoritarismo.

A expropriação da possibilidade de pensamento crítico é acompanhada pela semiformação que privilegia o saber técnico em detrimento do saber filosófico, obstruindo a reflexão sobre a educação. A atividade docente tem se reduzido em mera 


\section{SEMINÁRIO DE PESQUISA EM CIÊNCIAS HUMANAS - SEPECH \\ Humanidades, Estado e desafios didático-científicos \\ Londrina, 27 a 29 de julho de 2016}

técnica ou aplicação de conhecimentos produzidos pelas ciências da educação, atendendo à necessidade social de aumento da eficiência, à demanda de qualificação profissional e aos padrões de consumo. A formação vai dissolvendo-se como experiência formativa coisificada e esvaziada de conteúdos que se esgotam na própria relação formal com o conhecimento, impedindo que se forneçam ao professor formas para refletir sobre os problemas que enfrenta e para encontrar meios de solucioná-los ou, mesmo, traduzi-los e narrá-los como experiência.

Em contraposição, a escola deve ser um espaço de possibilidades emancipatórias, já que Adorno acredita que os processos formativos sejam possibilidades de se tornar o homem "civilizado". Nesse processo, o colapso educacional não se restringe meramente aos métodos ineficientes, ao contrário, manifesta-se pela crise da formação cultural, ou seja, pela crise da possibilidade de experiência do pensar crítico e auto-reflexivo. Quando a formação cultural reduz-se ao processo de semiformação/razão instrumental e ou (des) autoridade pedagógica, com a onipresença do espírito alienado e adaptado, o indivíduo é entregue a si mesmo e aos padrões do consumo e da mercadoria.

Em se tratando dos espaços formativos, essa influência é altamente preocupante, uma vez que os resultados desse processo, acabam sendo os educadores envolvidos por sentimento de impotência, de ilusão, que faz aumentar seus medos e angústias e se silenciar enquanto autoridade pedagógica. Nesse sentido, o embrutecimento e a neutralização da razão em espaços formativos acarreta ao professor o mero papel de "explicador" de saberes. Por mais que haja a preocupação com o pensamento reflexivo e transformador, o professor é subjugado pelo processo que domina e expropria a capacidade criadora e reflexiva. Horkheimer chama a atenção para o sintoma frequente do embrutecimento intelectual:

A hipocrisia amplamente difundida, a crença em falsas teorias, o desencorajamento do pensamento especulativo, a debilitação da vontade, ou o seu desvio precipitado em atividades intermináveis sob a pressão do medo é um sintoma dessa desproporção (HORKHEIMER, 2002 p.191)

A profissionalização docente, mesmo sendo influenciada pela lógica do consumo, pela Indústria Cultural e pelas modismos pedagógicos, que silenciam o pensamento crítico e criativo, pode e deve submeter-se a um trabalho que ultrapasse essa visão acrítica. Adorno afirma que o pensamento crítico pode permitir pelo embate teórico e metodológico a resistência e a negação na luta pela constituição de um pensamento crítico, criativo e expressivo.

Nesse sentido, é imprescindível que a educação se apresente como capaz de promover a emancipação, uma vez que se faz necessário que este profissional de educação desenvolva ações críticas desde as situações de planejamento educacional. Defende-se uma emancipação que permita a tomada de consciência pelos professores e alunos em que a individualidade seja formada propriamente no processo da experiência do pensar.

Se por evolução científica e progresso intelectual queremos significar a libertação do homem da crença supersticiosa em forças do mal, demônios e fadas, e no destino cego - em suma, a emancipação do 


\section{SEMINÁRIO DE PESQUISA EM CIÊNCIAS HUMANAS - SEPECH \\ Humanidades, Estado e desafios didático-científicos \\ Londrina, 27 a 29 de julho de 2016}

medo então - a denúncia daquilo que atualmente se chama de razão é o maior serviço que a razão pode prestar (HORKHEIMER, 2002 p.192).

Dessa forma, pensar a experiência formativa, apreendida em seu sentido emancipatório, abre a perspectiva de resistência ao saber instituído. Para tanto, parte-se do pressuposto de que é por meio da educação que podemos pensar a constituição de um sujeito autônomo, na difícil tarefa de transformação do mundo. Desse modo, acredita-se que a educação constitui o palco no qual é possível tornar a ação humana significativa no mundo à luz da emancipação. Nesse sentido, para Adorno (1995) a importância da educação está muito além da simples transmissão de conhecimentos. A atenção deve-se voltar para o preparo do cidadão para a convivência em sociedade e para a emancipação. A emancipação diz respeito à condução para a liberdade intelectual, capacidade de convivência saudável e paulatinamente o desenvolvimento do cidadão para que tenha a possibilidade de fazer suas escolhas com responsabilidade e justiça. Deste modo, a emancipação social pressupõe reflexão e coragem de enfrentar os conflitos e tensões que se apresentam nas relações e contradições vividas pela sociedade atual.

Arendt traz uma importante contribuição para que o exercício crítico e reflexivo devolva aos espaços educativos novos horizontes do ensino. Como estratégias para possíveis saídas da crise, acredita-se que nas horas de aula o profissional precisa se assumir no papel de conhecedor e detentor do conhecimento, com compromisso e seriedade no que envolve o processo de ensino e aprendizagem. Além disso, seria fundamental ressignificar o olhar para os cursos de formação desses profissionais da educação, com perspectivas de valorização do currículo de formação e preparação profissional dos mesmos e, por fim, transformar o atual currículo de formação de professores, com aprimoramentos dos processos de formação antes de iniciarem seu

trabalho juntos às crianças. Nessa reflexão, é preciso avançar as discussões no campo da relação docente e de alunos, superando práticas ativistas, que tornam o ensino e a formação, mera adaptação social em um contexto amplamente utilitarista.

É preciso, desse modo, compreender o processo de educação e de formação, bem como analisar as especificidades da criança, a qual nada mais é do que o sujeito da educação, um ser "novo" para um mundo que lhe é estranho e que, acima de tudo, se encontra em processo de formação. Diante disso, Arendt (2013 p.235) complementa essa ideia ao afirmar que a "criança partilha o estado de vir a ser com todas as coisas vivas; com respeito à vida e seu desenvolvimento, a criança é um ser humano em processo de formação [...]"; sendo portanto, necessário um trabalho de mediação e intervenção docente comprometido com o conhecimento e com a própria vida deste sujeito infantil.

O papel pedagógico docente deve ser o de assumir sua responsabilidade pelo ensino e pelo conhecimento à luz dos conceitos emancipatórios. Na educação, essa responsabilidade assume a forma de autoridade pedagógica que jamais deve ser exercida de forma arbitrária. Arendt (2013 p.240) deixa clara a ideia de que na modernidade a autoridade foi recusada pelos adultos, e isso somente pode significar uma coisa: "que os adultos se recusam a assumir a responsabilidade pelo mundo ao qual trouxeram as crianças". Para que essa autoridade se reafirme na sociedade atual, há a 


\section{SEMINÁRIO DE PESQUISA EM CIÊNCIAS HUMANAS - SEPECH \\ Humanidades, Estado e desafios didático-científicos \\ Londrina, 27 a 29 de julho de 2016}

defesa do pensamento auto reflexivo e da autocritica estabelecida por Adorno, com a finalidade de trabalhar na direção de identificação da barbárie atual, com o objetivo de poder transformá-la. Para tanto, as ações emancipatórias podem se iniciar desde o trabalho formativo voltado à primeira infância, quando no processo de emancipação, os profissionais pedagógicos possam fazer uso da própria palavra, se servindo de seu próprio entendimento e, se aproximando da conscientização e da racionalidade; mesmo que esta esteja, muitas vezes, mergulhada na irracionalidade.

Adorno e Horkheimer (1985) provocam-nos no Prefácio da obra Dialética do Esclarecimento ao dizer que a "humanidade, em vez de entrar em um estado verdadeiramente humano, está se afundando em uma nova espécie de barbárie". Complementa, ainda, que "o preço das grandes invenções é a ruina progressiva da cultura teórica". Para tanto, pode-se pensar que uma educação que procura evitar a volta à barbárie deverá se concentrar na educação com vistas à emancipação. Assim, desde a primeira infância, quanto melhor forem esclarecidas as crianças, mais chances elas terão de formarem seu ego e ajudar a criar um ambiente mais humano (ADORNO, 1995). Desse modo, essas reflexões suscitam-nos a pensar em novos direcionamentos pedagógicos, apontando desafios e possíveis avanços no campo da educação e do trabalho pedagógico voltado a uma ação educativa com vistas a emancipação.

\section{REFERÊNCIAS}

ADORNO, T.W. Educação e Emancipação. Trad. Wolfgang L. Maar. Rio de Janeiro: Paz e Terra, 1995.

ADORNO, T.W. HORKHEIMER, M. Dialética do Esclarecimento. Trad. Guido Antônio de Almeida. Rio de Janeiro: Jorge Zahar Ed., 1985.

ARENDT, Hannah. Entre o passado e o futuro. Tradução Mauro W. Barbosa de Almeida. $1^{\text {a }}$ reimpressão da $7^{\mathrm{a}} \mathrm{ed}$. São Paulo: Perspectiva, 2013.

CATTIN, Yves. O ser humano: Transgressor de Fronteiras. Revista Concilium, 280, 1999/2. Petrópolis: Vozes. p. 27.

FERRAZ, Tércio de. Política e ciência política. Brasília. Editora UnB, 1978 (Coleção Textos de Aula).

HORKHEIMER, Max. Eclipse da Razão. Tradução de Sebastião Uchoa Leite. São Paulo: Centauro, 2002.

PUCCI, et ali (org). Teoria Crítica e Inconformismo: novas perspectivas da pesquisa. Campinas, São Paulo: Autores Associados, 2010 - Coleção Educação Contemporânea. 